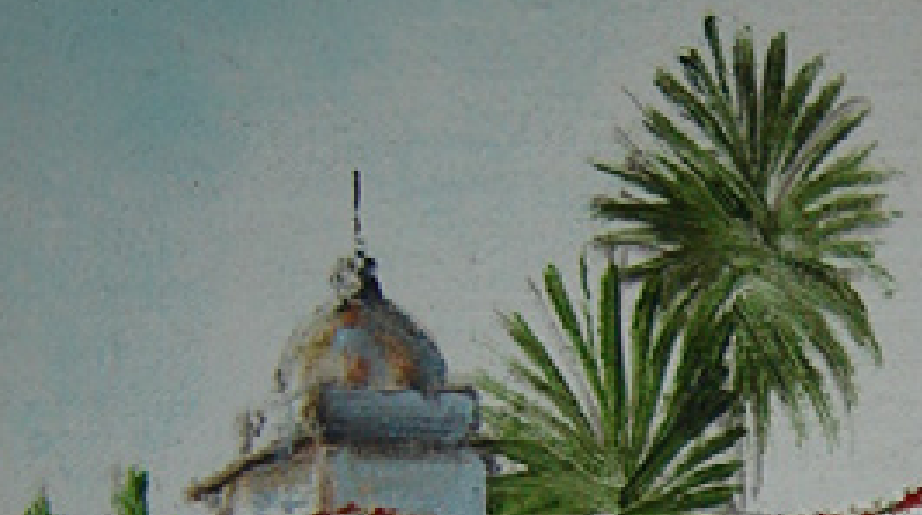

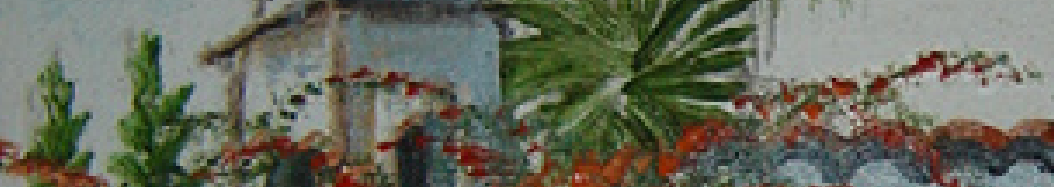

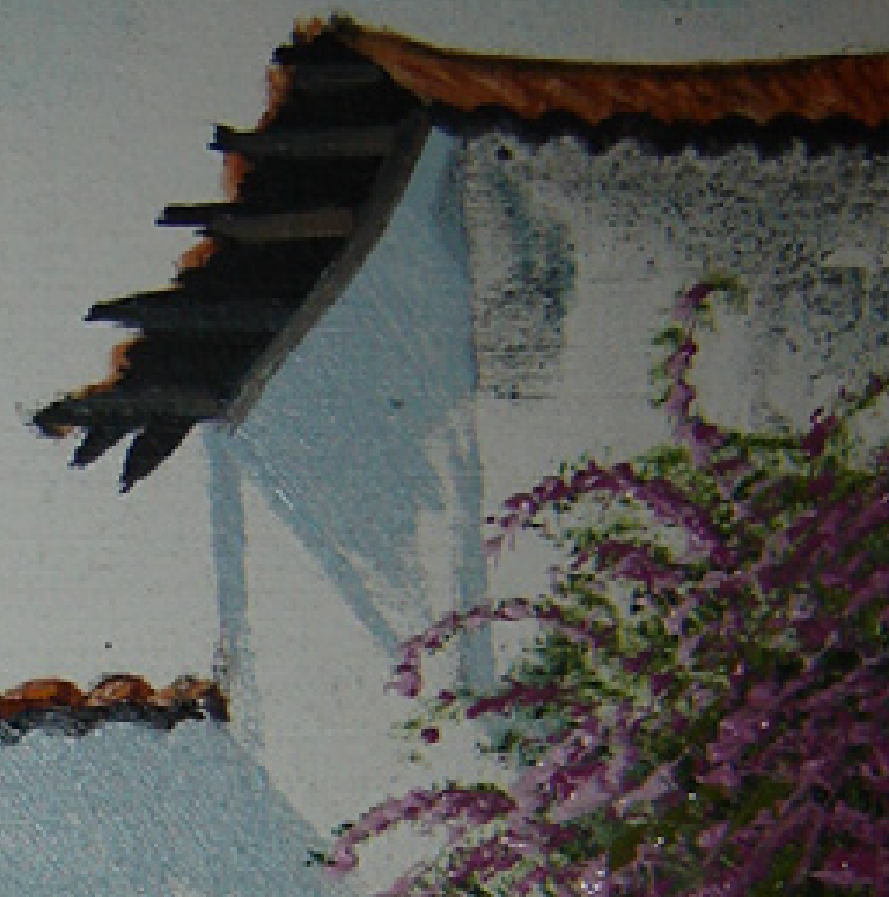

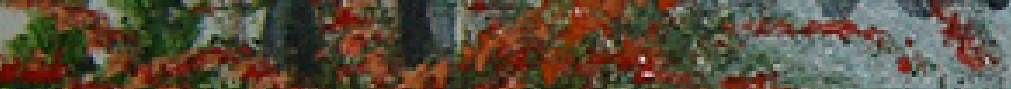
3.

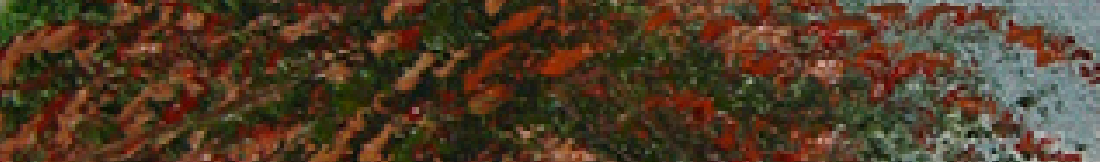

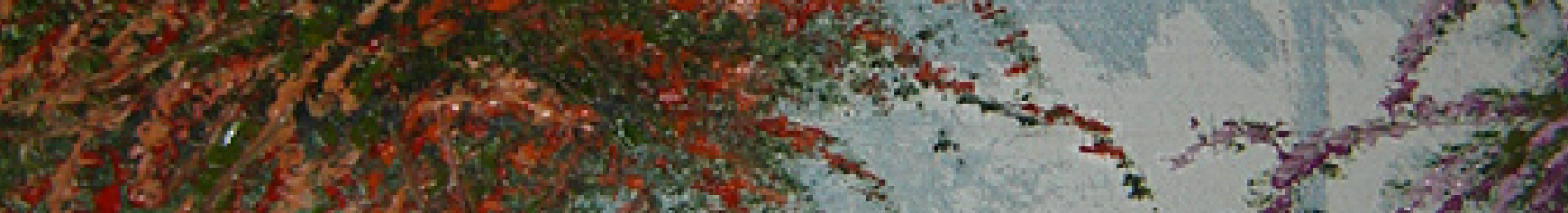

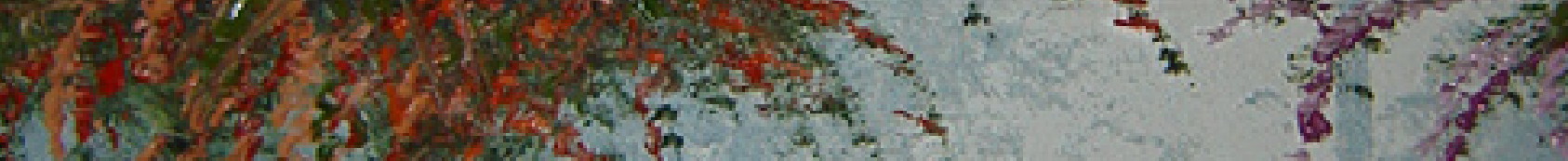
2. $8+\frac{1}{2} \frac{1}{2}$

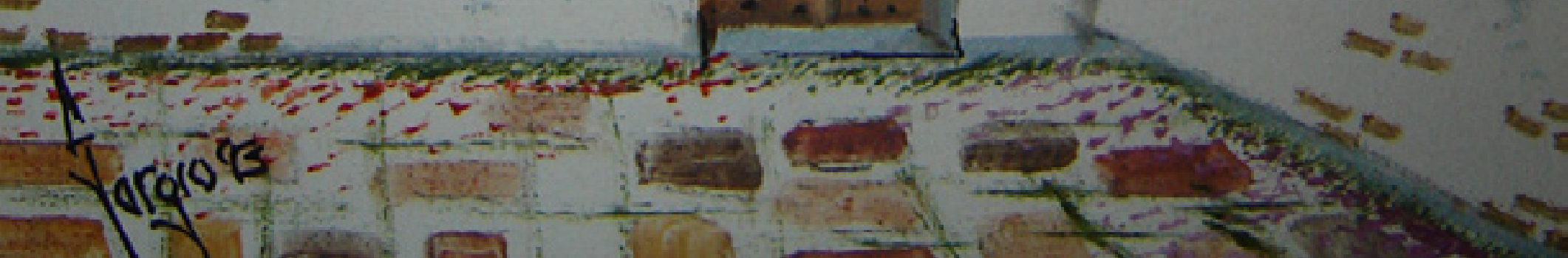




\section{2 migración interna intermunicipal de Honduras}

Manuel Antonio FloRes FonseCa

\section{INTRODUCCIÓN}

La migración es una de las principales variables demográficas y mide los diferentes movimientos de la población que rebasan una frontera geográfica específica para adoptar otra residencia en carácter permanente. Esta frontera puede ser un lugar poblado donde se nace o se reside, un caserío o ciudad, aldea, municipio, departamento, región o país. La migración interna mide los desplazamientos dentro de un país y la internacional fuera del país.

La importancia que en los últimos años han tomado los gobiernos locales, con la descentralización de acciones gubernamentales a los municipios, indica que estos deben de planificar sus acciones tomando en cuenta la información científica para una mejor toma de decisiones. En este sentido la información demográfica y específicamente la migratoria es útil en la planificación del desarrollo local.

Este trabajo de investigación quiere llenar el vacío de información demográfica en la variable migración interna a nivel departamental y especialmente municipal como una contribución a la generación de conocimiento y que sea utilizada por los municipios.

\section{ANTECEDENTES}

Para llenar los vacíos de estudios regionales sobre migración interna con datos censales, el Centro Latinoamericano de Demografía (CELADE) utilizando el software de Recuperación de Datos Para Áreas Menores (REDATAM) procesa más de veinte bases censales de países de América Latina y El Caribe con el objetivo entre otros de verificar la magnitud y sentido de los flujos y las características de los migrantes internos en los países de la región. Estos hallazgos son presentados en el trabajo de investigación titulado "Migración Interna en América Latina y El Caribe: Estudio Regional del Período 1980-2000". ${ }^{1}$

Utilizando la potencialidad de los censos se cuantifican los flujos migratorios internos entre otros aspectos, entre las metas se construyeron matrices de migración absoluta y reciente entre DAM y DAME. En este aspecto los principales hallazgos del estudio fueron: a) la disparidad de la intensidad histórica de la migración interna entre países de la región: los acervos de migrantes absolutos entre DAM van desde el 30\% en Paraguay hasta 15\% en Nicaragua y los migrantes absolutos entre DAME van desde el 19\% en Nicaragua hasta el $50 \%$ en Chile b) estas cifras no llevan a conclusiones directas, pues las afectan factores intrínsecos a la movilidad; algunos relacionados con la captación de la migración -como la extensión y la cantidad de DAM y DAME y la modificación de los límites político adminis-

1 Rodríguez Vignoli, Jorge. Migración Interna en América Latina y El Caribe: Estudio Regional del Periodo 1980-2000, Serie Población y Desarrollo 50, Santiago de Chile, CELADE-CEPAL, 2004.

2 Idem 1. trativos- y otros aspectos sustantivos, como la estructura etaria de la población, c) Se constata que, para la mayoría de las personas de los países examinados, su entorno inmediato de residencia habitual (la DAME en que residen) coincide con aquel en que nacieron, lo que sugiere un grado de arraigo y de conocimiento de la realidad local importante.

Con relación a los valores de migración interna de toda la vida y medidas estimados por CELADE a nivel de DAM encontramos una diferencia en la estimación de la población censal relevante de Honduras del 2001, aunque la proporción de migrantes estimada en este trabajo difiere levemente. A nivel de DAME utilizamos la matriz construida por CELADE para 1988, no en el caso del censo del 2001 que construimos la matriz de migración y se hicieron las estimaciones que arrojaron un número de migrantes absolutos entre DAME de 1,390,823, la población censal relevante se estimó en 5,963,794 para calcular una proporción de $23.32 \%$ de migrantes absolutos entre DAME en Honduras.

En los valores y medidas estimados de migración interna reciente por CELADE a nivel de DAM encontramos una diferencia leve en la estimación de la población censal relevante de Honduras del 2001 y la tasa media anual de migración estimada en este trabajo, pero dicha diferencia se debe a la inclusión de ignorados. A nivel de DAME utilizamos la matriz construida por CELADE para 1988, mientras que del censo del 2001 construimos la matriz de migración reciente y se hicieron las estimaciones que arrojaron un número de migrantes recientes entre DAME de 312,622, la población censal relevante se estimó en 5,166,813 para calcular una tasa media anual de migración entre DAME de 12.10 por mil para Honduras.

En resumen, tanto a nivel de DAM y DAME Honduras presenta un nivel de baja movilidad al compararlo con los demás países de Latinoamérica ya sea en la migración absoluta como en la reciente. Para CELADE, es sorprendente el nivel de Nicaragua y Honduras en la menor proporción de migrantes absolutos habida cuenta de su extensión más bien pequeña y la cantidad de departamentos con que cuentan y los niveles sobresalientes de pobreza puede estar en la base de una migración menos intensa, ya que hay menos holguras financieras para solventar los costos de los traslados. ${ }^{2}$

\section{METODOLOGÍA}

La principal fuente de datos de esta investigación es el Censo de Población y Vivienda del 2001. Este censo ejecutado bajo la modalidad de jure o de derecho utilizó el concepto de hogar unidad doméstica, como unidad de empadronamiento que se acerca más a la realidad en la determinación de hogares dentro de las viviendas.

Con tres preguntas básicas se calcula directamente matrices de migración así; con la pregunta de lugar de nacimiento y lugar de empadronamiento se estima la matriz de migración interna acumulada 
hasta la fecha censal (migración de toda la vida), con la pregunta de lugar de empadronamiento y lugar de residencia cinco años antes del censo (1996) se construye una matriz de migración interna reciente. En ambas matrices al eliminar la diagonal (no migrantes) se estiman los orígenes y destinos y los volúmenes de inmigrantes y emigrantes.

\section{MIGRACIÓN INTERNA INTERMUNICIPAL DE TODA LA VIDA}

\subsection{Volumen}

La proporción de población nativa residente en un municipio diferente al municipio de su nacimiento ha tenido una reducción en los últimos censos hondureños; de 27.5\% en 1988 descendió a $23.3 \%$ en el 2001. Sin embargo, el número de migrantes internos intermunicipales se incrementó en este período de 1,130,464 personas en 1988 a 1,390,823 personas en el 2001, que equivale a una tasa de crecimiento de $1.57 \%$.

Cuadro No. 1. Honduras: Municipios con mayor número de emigrantes de toda la vida, 1988 y 2001.

\begin{tabular}{|c|c|c|c|c|c|}
\hline Cod & $\begin{array}{l}\text { Munici- } \\
\text { pios }\end{array}$ & $\begin{array}{l}\text { Emigran- } \\
\text { tes } 1988\end{array}$ & Cod & $\begin{array}{l}\text { Munici- } \\
\text { pios }\end{array}$ & $\begin{array}{l}\text { Emigran- } \\
\text { tes } 2001\end{array}$ \\
\hline 501 & $\begin{array}{l}\text { San Pedro } \\
\text { Sula }\end{array}$ & 61.457 & 501 & $\begin{array}{l}\text { San Pedro } \\
\text { Sula }\end{array}$ & 79.772 \\
\hline 801 & $\begin{array}{l}\text { Distrito } \\
\text { Central }\end{array}$ & 45.090 & 801 & $\begin{array}{l}\text { Distrito } \\
\text { Central }\end{array}$ & 70.398 \\
\hline 1804 & El Progreso & 25.217 & 101 & La Ceiba & 29.062 \\
\hline 107 & Tela & 22.200 & 107 & Tela & 28.827 \\
\hline 101 & La Ceiba & 21.815 & 1804 & El Progreso & 27.490 \\
\hline 601 & Choluteca & 21.587 & 601 & Choluteca & 27.180 \\
\hline 1807 & Olanchito & 18.656 & 703 & Danlí & 26.778 \\
\hline 1501 & Juticalpa & 18.074 & 401 & $\begin{array}{l}\text { Santa Rosa } \\
\text { de Copán }\end{array}$ & 24.637 \\
\hline 401 & $\begin{array}{l}\text { Santa Rosa } \\
\text { de Copán }\end{array}$ & 17.602 & 1501 & Juticalpa & 24.578 \\
\hline 1701 & Nacaome & 16.699 & 1807 & Olanchito & 23.590 \\
\hline 703 & Danlí & 15.887 & 1601 & $\begin{array}{l}\text { Santa } \\
\text { Bárbara }\end{array}$ & 22.767 \\
\hline 301 & Comayagua & 14.479 & 301 & Comayagua & 20.517 \\
\hline 611 & Pespire & 14.009 & 1701 & Nacaome & 17.234 \\
\hline 512 & La Lima & 12.376 & 1801 & Yoro & 16.680 \\
\hline 1601 & $\begin{array}{l}\text { Santa } \\
\text { Bárbara }\end{array}$ & 11.635 & 611 & Pespire & 15.525 \\
\hline 318 & $\begin{array}{l}\text { Siguatepe- } \\
\text { que }\end{array}$ & 11.161 & 318 & $\begin{array}{l}\text { Siguatepe- } \\
\text { que }\end{array}$ & 14.405 \\
\hline 1707 & Langue & 10.646 & 209 & Tocoa & 13.244 \\
\hline 615 & $\begin{array}{l}\text { San Marcos } \\
\text { de Colón }\end{array}$ & 10.615 & 512 & La Lima & 13.042 \\
\hline 1612 & Macuelizo & 10.472 & 1612 & Macuelizo & 12.231 \\
\hline 208 & Sonaguera & 9.780 & 1503 & Catacamas & 11.441 \\
\hline 605 & El Corpus & 9.373 & 615 & $\begin{array}{l}\text { San Marcos } \\
\text { de Colón }\end{array}$ & 11.357 \\
\hline
\end{tabular}

Fuente: Elaboración propia en base a datos censales 1988 y 2001.

\subsection{Emigrantes}

Los municipios con mayor número de emigrantes internos de toda la vida son San Pedro Sula y el Distrito Central que albergan a las dos ciudades principales del país (expulsan el 11\% de los emigrantes). Otros municipios con mayor número de emigrantes son aquellos que albergan a ciudades intermedias y las excepciones son pocas. En el período, tanto en 1988 como en el 2001 generalmente los principales municipios expulsores de población son los mismos (cuadro No. 1).

En cambio, los municipios con los mayores porcentajes de emigrantes con respecto a la población que nació allí, independiente que vivan actualmente, son aquellos donde el impacto de la emigración es más notorio y son generalmente pequeños y poco poblados, aunque en ellos con excepción están La Esperanza, Santa Bárbara y Santa Rosa de Copán que son municipios que albergan ciudades intermedias. Algunos de ellos el impacto ha sido tal que superan la mitad de

Cuadro No. 2. Honduras: Municipios con mayor porcentaje de emigrantes de toda la vida, 1988 y 2001.

\begin{tabular}{|c|c|c|c|c|c|}
\hline Cod & Municipios & $\begin{array}{c}\text { \% Emi- } \\
\text { gración } \\
1988\end{array}$ & Cod & Municipios & $\begin{array}{c}\% \text { Emi- } \\
\text { gración } \\
2001\end{array}$ \\
\hline 1209 & $\begin{array}{l}\text { Mercedes de } \\
\text { Oriente }\end{array}$ & 62.19 & 1001 & La Esperanza & 62.02 \\
\hline 1001 & La Esperanza & 59.77 & 1209 & $\begin{array}{l}\text { Mercedes de } \\
\text { Oriente }\end{array}$ & 54.45 \\
\hline 718 & Yauyupe & 56.89 & 1211 & $\begin{array}{l}\text { San Antonio } \\
\text { del Norte }\end{array}$ & 52.25 \\
\hline 1211 & $\begin{array}{l}\text { San Antonio } \\
\text { Del Norte }\end{array}$ & 56.71 & 718 & Yauyupe & 50.90 \\
\hline 818 & $\begin{array}{l}\text { San Buena- } \\
\text { ventura }\end{array}$ & 56.31 & 1601 & $\begin{array}{l}\text { Santa } \\
\text { Bárbara }\end{array}$ & 49.84 \\
\hline 312 & Ojos de Agua & 54.02 & 608 & Morolica & 47.47 \\
\hline 1704 & Aramecina & 53.17 & 821 & $\begin{array}{l}\text { San Migue- } \\
\text { lito }\end{array}$ & 47.33 \\
\hline 608 & Morolica & 52.71 & 818 & $\begin{array}{l}\text { San Buena- } \\
\text { ventura }\end{array}$ & 47.27 \\
\hline 821 & San Miguelito & 51.75 & 401 & $\begin{array}{l}\text { Santa Rosa } \\
\text { de Copán }\end{array}$ & 46.75 \\
\hline 408 & Dulce Nombre & 51.48 & 812 & $\begin{array}{l}\text { Nueva Arme- } \\
\text { nia }\end{array}$ & 46.14 \\
\hline 416 & San Jerónimo & 50.46 & 408 & $\begin{array}{l}\text { Dulce } \\
\text { Nombre }\end{array}$ & 46.02 \\
\hline 812 & $\begin{array}{l}\text { Nueva } \\
\text { Armenia }\end{array}$ & 48.84 & 1705 & Caridad & 44.52 \\
\hline 1705 & Caridad & 48.68 & 613 & San Isidro & 43.51 \\
\hline 1403 & Concepción & 48.25 & 416 & SanJerónimo & 43.11 \\
\hline 1010 & San Antonio & 48.17 & 1704 & Aramecina & 42.69 \\
\hline 1623 & $\begin{array}{l}\text { San Pedro } \\
\text { Zacapa }\end{array}$ & 48.13 & 1010 & San Antonio & 42.63 \\
\hline 1203 & Cabañas & 47.94 & 1307 & Guarita & 41.75 \\
\hline 807 & La Libertad & 47.80 & 1326 & Valladolid & 41.69 \\
\hline 1307 & Guarita & 47.71 & 1406 & $\begin{array}{l}\text { La Encarna- } \\
\text { ción }\end{array}$ & 41.22 \\
\hline 1015 & Santa Lucía & 47.21 & 611 & Pespire & 41.17 \\
\hline
\end{tabular}

Fuente: Elaboración propia en base a da os censales 1988 y 2001. 
las poblaciones que nacieron en el municipio. Generalmente el historial de mayor impacto emigratorio se repite en los mismos municipios tanto en 1988 como en el 2001 (cuadro No. 2).

\subsection{Inmigrantes}

Los municipios con mayor número de inmigrantes de toda la vida son casualmente casi los mismos que tienen mayores volúmenes de emigrantes, tal es el caso de las que ubican a las dos principales ciudades del país (atraen el 28\% de los inmigrantes) y algunas ciudades intermedias, excepciones son municipios con características netamente emigratorias como Choluteca, Danlí, Juticalpa y otros pequeños. Los municipios de Choloma y Villanueva se han convertido en los puntos atractivos para la inmigración porque en ellos se concentran parques industriales que albergan industrias maquiladoras que absorben mano de obra (cuadro No. 3).

Algunos municipios tienen su atracción al estar cerca de la frontera agrícola ahora o en el pasado reciente, tal es el caso de Tocoa, Trojes, Catacamas y Olanchito.

El impacto de la inmigración ha sido en algunos municipios superior al cincuenta por ciento y generalmente son municipios poco poblados con origen inmigratorio de colonización agrícola; otros por ser atractivos para insertarse en empleos del sector turismo y la excepción de algunos como Villanueva, Choloma, donde el impacto se debe al enorme flujo inmigratorio por las maquilas y se han convertido en municipios muy poblados (cuadro No. 4).

\subsection{Saldo migratorio}

En el saldo migratorio interno de toda la vida, que es la diferencia entre inmigrantes y emigrantes, los municipios con mayores saldos positivos son los que albergan a las dos grandes ciudades del país (Distrito Central y San Pedro Sula), municipios atractivos por la industria maquiladora (Choloma, Villanueva, Puerto Cortés, El Progreso), ciudades intermedias y algunos de frontera agrícola o cercanos a ella (Patuca, Trojes, Tocoa, Bonito Oriental, Catacamas), por industria turística como Roatán (cuadro No. 5 y Figura No. 1).

Los municipios con mayor saldo migratorio negativo son aquellos donde la emigración es mayor que la inmigración y son generalmente municipios expulsores de población de tradición del occidente del país (Santa Bárbara, Santa Rosa de Copán, Ocotepeque, San José de Colinas), o en el litoral norte (Tela, Yoro, Olanchito) generalmente a San Pedro Sula. Otros son municipios del área sur, oriente y oeste que generalmente expulsan población al Distrito Central (cuadro No. 6).

Figura No. 1. Saldo migratorio de toda la vida, 2001

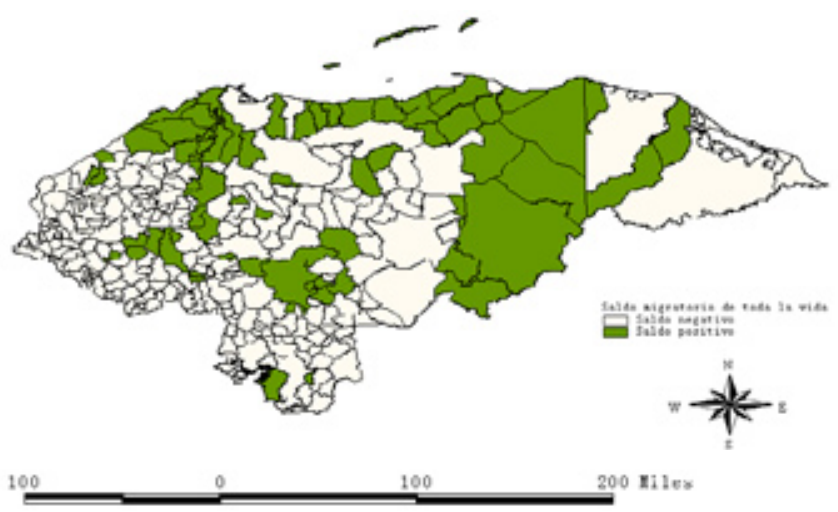

Diagrama No. 1. Flujos migratorios de toda la vida, 2001 (mayores 2000 personas)

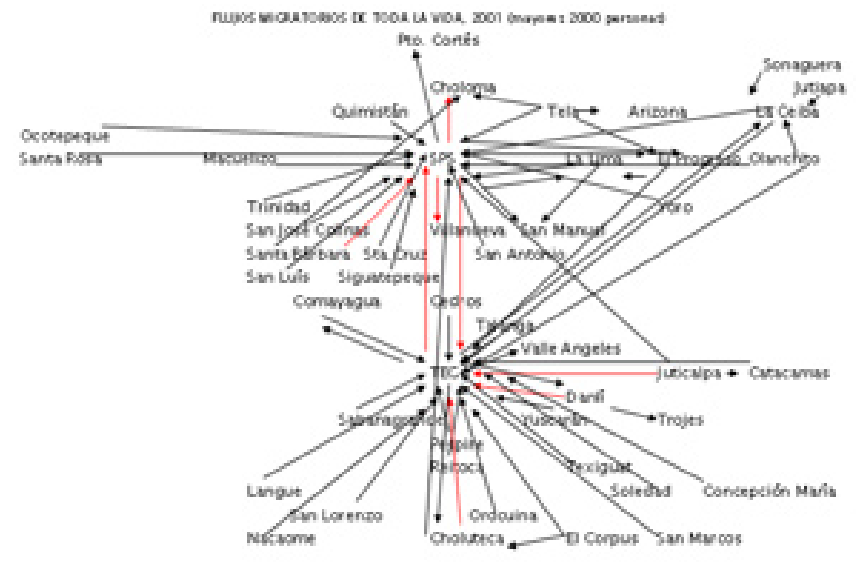

Diagrama No. 2. Flujos migratorios recientes, 2001-1996 (mayores 1000 personas

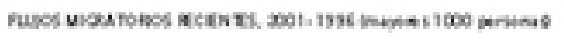

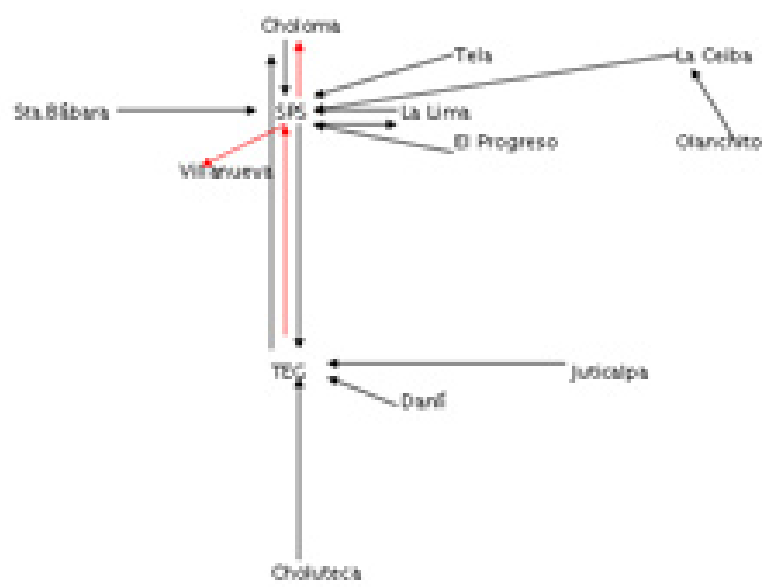

Figura No. 2. Saldo migratorio reciente, 2001-1996

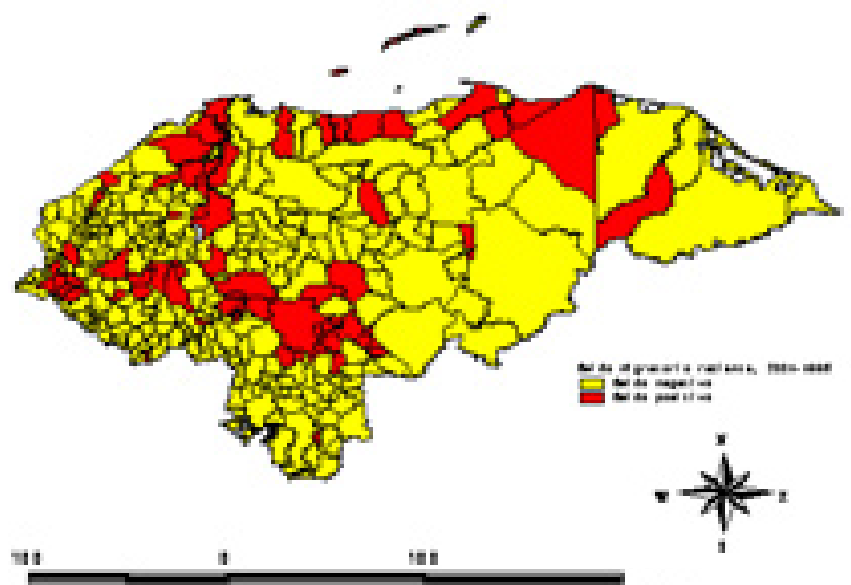


Cuadro No. 3. Honduras: Municipios con mayor número de inmigrantes de toda la vida, 1988 y 2001.

\begin{tabular}{|c|c|c|c|c|c|}
\hline Cod & $\begin{array}{c}\text { Munici- } \\
\text { pios }\end{array}$ & $\begin{array}{c}\text { Inmigran- } \\
\text { tes } 1988\end{array}$ & Cod & $\begin{array}{l}\text { Munici- } \\
\text { pios }\end{array}$ & $\begin{array}{l}\text { Inmigran- } \\
\text { tes } 2001\end{array}$ \\
\hline 801 & $\begin{array}{l}\text { Distrito } \\
\text { Central }\end{array}$ & 195.697 & 801 & $\begin{array}{l}\text { Distrito } \\
\text { Central }\end{array}$ & 210.716 \\
\hline 501 & $\begin{array}{l}\text { San } \\
\text { Pedro } \\
\text { Sula }\end{array}$ & 122.478 & 501 & $\begin{array}{l}\text { San Pedro } \\
\text { Sula }\end{array}$ & 172.32 \\
\hline 1804 & $\begin{array}{l}\text { El Progre- } \\
\text { so }\end{array}$ & 38.580 & 502 & Choloma & 72.849 \\
\hline 502 & Choloma & 33.613 & 511 & Villanueva & 40.611 \\
\hline 101 & La Ceiba & 28.537 & 1804 & $\begin{array}{l}\text { El Pro- } \\
\text { greso }\end{array}$ & 40.054 \\
\hline 512 & La Lima & 27.118 & 101 & La Ceiba & 39.541 \\
\hline 107 & Tela & 21.878 & 512 & La Lima & 27.613 \\
\hline 506 & $\begin{array}{l}\text { Puerto } \\
\text { Cortes }\end{array}$ & 20.563 & 506 & $\begin{array}{l}\text { Puerto } \\
\text { Cortés }\end{array}$ & 24.081 \\
\hline 601 & $\begin{array}{l}\text { Cholu- } \\
\text { teca }\end{array}$ & 18.640 & 703 & Danlí & 20.836 \\
\hline 703 & Danlí & 18.226 & 510 & $\begin{array}{l}\text { Santa } \\
\text { Cruz de } \\
\text { Yojoa }\end{array}$ & 20.156 \\
\hline & $\begin{array}{l}\text { Santa } \\
\text { Cruz De }\end{array}$ & & & & \\
\hline 510 & Yojoa & 16.598 & 601 & Choluteca & 19.756 \\
\hline 103 & Esparta & 16.104 & 107 & Tela & 19.26 \\
\hline 209 & Tocoa & 15.887 & 209 & Tocoa & 18.904 \\
\hline 511 & $\begin{array}{l}\text { Villanue- } \\
\text { va }\end{array}$ & 14.942 & 1503 & $\begin{array}{l}\text { Cataca- } \\
\text { mas }\end{array}$ & 18.453 \\
\hline 1503 & $\begin{array}{l}\text { Cataca- } \\
\text { mas }\end{array}$ & 14.562 & 318 & $\begin{array}{l}\text { Siguate- } \\
\text { peque }\end{array}$ & 18.393 \\
\hline 301 & $\begin{array}{l}\text { Comaya- } \\
\text { gua }\end{array}$ & 14.393 & 301 & $\begin{array}{l}\text { Comaya- } \\
\text { gua }\end{array}$ & 17.676 \\
\hline 208 & $\begin{array}{l}\text { Sona- } \\
\text { guera }\end{array}$ & 13.606 & 509 & $\begin{array}{l}\text { San } \\
\text { Manuel }\end{array}$ & 16.705 \\
\hline 1501 & Juticalpa & 13.392 & 1807 & Olanchito & 15.747 \\
\hline 201 & Trujillo & 13.312 & 201 & Trujillo & 15.379 \\
\hline 318 & $\begin{array}{l}\text { Siguate- } \\
\text { peque }\end{array}$ & 12.942 & 1501 & Juticalpa & 13.032 \\
\hline 1807 & Olanchito & 12.575 & 719 & Trojes & 12.212 \\
\hline
\end{tabular}

Fuente: Elaboración propia en base a datos censales 1988 y 2001.
Cuadro No. 4. Honduras: Municipios con mayor porcentaje de inmigrantes de toda la vida, 1988 y 2001.

\begin{tabular}{|c|c|c|c|c|c|}
\hline Cod & $\begin{array}{l}\text { Munici- } \\
\text { pios }\end{array}$ & $\begin{array}{c}\% \text { Inmi- } \\
\text { gración } \\
1988\end{array}$ & Cod & $\begin{array}{l}\text { Munici- } \\
\text { pios }\end{array}$ & $\begin{array}{c}\% \text { Inmi- } \\
\text { gración } \\
2001\end{array}$ \\
\hline 512 & La Lima & 64.15 & 1017 & $\begin{array}{l}\text { San } \\
\text { Francisco de } \\
\text { Opalaca }\end{array}$ & 68.77 \\
\hline 210 & $\begin{array}{l}\text { Bonito } \\
\text { Oriental }\end{array}$ & 63.05 & 509 & San Manuel & 56.12 \\
\hline 509 & San Manuel & 56.55 & 108 & Arizona & 54.01 \\
\hline 102 & El Porvenir & 56.50 & 512 & La Lima & 53.08 \\
\hline 719 & Trojes & 54.91 & 511 & Villanueva & 52.33 \\
\hline 502 & Choloma & 54.37 & 502 & Choloma & 49.88 \\
\hline 201 & Trujillo & 52.50 & 1101 & Roatán & 48.74 \\
\hline 106 & $\begin{array}{l}\text { San Fran- } \\
\text { cisco }\end{array}$ & 52.33 & 504 & Pimienta & 48.50 \\
\hline 205 & Sabá & 52.30 & 1104 & Utila & 48.31 \\
\hline 202 & Balfate & 51.72 & 320 & Las Lajas & 44.18 \\
\hline 1627 & Las Vegas & 51.58 & 210 & $\begin{array}{l}\text { Bonito } \\
\text { Oriental }\end{array}$ & 43.39 \\
\hline 103 & Esparta & 50.64 & 106 & $\begin{array}{l}\text { San Fran- } \\
\text { cisco }\end{array}$ & 40.23 \\
\hline 204 & Limón & 49.38 & 202 & Balfate & 40.05 \\
\hline 209 & Тосоа & 48.64 & 205 & Sabá & 39.88 \\
\hline 105 & La Masica & 48.60 & 505 & Potrerillos & 39.09 \\
\hline 208 & Sonaguera & 47.66 & 104 & Jutiapa & 39.02 \\
\hline 504 & Pimienta & 47.32 & 1523 & Patuca & 38.93 \\
\hline 511 & Villanueva & 46.88 & 102 & El Porvenir & 38.90 \\
\hline 1101 & Roatán & 45.98 & 204 & Limón & 38.76 \\
\hline 508 & $\begin{array}{l}\text { San Francis- } \\
\text { co De Yojoa }\end{array}$ & 45.54 & 508 & $\begin{array}{l}\text { San Francis- } \\
\text { co de Yojoa }\end{array}$ & 38.37 \\
\hline
\end{tabular}

Fuente: Elaboración propia en base a datos censales 1988 y 2001. 
Cuadro No. 5. Honduras: Municipios con mayor saldo migratorio positivo de toda la vida, 1988 y 2001.

\begin{tabular}{|c|c|c|c|c|c|}
\hline Cod & $\begin{array}{l}\text { Munici- } \\
\text { pios }\end{array}$ & $\begin{array}{l}\text { Migración } \\
\text { Neta } 1988\end{array}$ & Cod & Municipios & $\begin{array}{l}\text { Migra- } \\
\text { ción Neta } \\
2001\end{array}$ \\
\hline 801 & $\begin{array}{l}\text { Distrito } \\
\text { Central }\end{array}$ & 150.607 & 801 & $\begin{array}{l}\text { Distrito } \\
\text { Central }\end{array}$ & 140.318 \\
\hline 501 & $\begin{array}{l}\text { San Pedro } \\
\text { Sula }\end{array}$ & 61.021 & 501 & $\begin{array}{l}\text { San Pedro } \\
\text { Sula }\end{array}$ & 92.548 \\
\hline 502 & Choloma & 26.223 & 502 & Choloma & 64.379 \\
\hline 512 & La Lima & 14.742 & 511 & Villanueva & 34.59 \\
\hline 1804 & El Progreso & 13.363 & 506 & Puerto Cortés & 16.199 \\
\hline 506 & $\begin{array}{l}\text { Puerto } \\
\text { Cortes }\end{array}$ & 11.843 & 512 & La Lima & 14.571 \\
\hline 103 & Esparta & 10.171 & 509 & San Manuel & 14.202 \\
\hline 719 & Trojes & 10.135 & 1804 & El Progreso & 12.564 \\
\hline 511 & Villanueva & 9.150 & 510 & $\begin{array}{l}\text { Santa Cruz } \\
\text { de Yojoa }\end{array}$ & 10.688 \\
\hline 510 & $\begin{array}{l}\text { Santa Cruz } \\
\text { De Yojoa }\end{array}$ & 8.906 & 101 & La Ceiba & 10.479 \\
\hline 209 & Tocoa & 8.206 & 719 & Trojes & 9.403 \\
\hline 1503 & Catacamas & 7.550 & 108 & Arizona & 8.362 \\
\hline 210 & $\begin{array}{l}\text { Bonito } \\
\text { Oriental }\end{array}$ & 7.331 & 210 & $\begin{array}{l}\text { Bonito } \\
\text { Oriental }\end{array}$ & 7.157 \\
\hline 1803 & El Negrito & 6.988 & 1503 & Catacamas & 7.012 \\
\hline 101 & La Ceiba & 6.722 & 1523 & Patuca & 6.457 \\
\hline 509 & San Manuel & 6.262 & 1101 & Roatán & 5.663 \\
\hline 201 & Trujillo & 5.018 & 209 & Tocoa & 5.660 \\
\hline 1627 & Las Vegas & 4.858 & 1017 & $\begin{array}{l}\text { San Francisco } \\
\text { de Opalaca }\end{array}$ & 4.555 \\
\hline & $\begin{array}{l}\text { Dulce } \\
\text { Nombre De }\end{array}$ & & & & \\
\hline 1505 & Culmí & 4.646 & 201 & Trujillo & 4.513 \\
\hline 321 & Taulabé & 4.427 & 504 & Pimienta & 4.319 \\
\hline 1617 & Quimistán & 4.081 & 318 & Siguatepeque & 3.988 \\
\hline
\end{tabular}

Fuente: Elaboración propia en base a datos censales 1988 y 2001.
Cuadro No. 6. Honduras: Municipios con mayor saldo migratorio negativo de toda la vida, 1988 y 2001.

\begin{tabular}{|c|c|c|c|c|c|}
\hline Cod & $\begin{array}{l}\text { Munici- } \\
\text { pios }\end{array}$ & $\begin{array}{l}\text { Migra- } \\
\text { ción Neta } \\
1988\end{array}$ & Cod & $\begin{array}{c}\text { Munici- } \\
\text { pios }\end{array}$ & $\begin{array}{l}\text { Migra- } \\
\text { ción Neta } \\
2001\end{array}$ \\
\hline 611 & Pespire & -12.669 & 1601 & $\begin{array}{l}\text { Santa } \\
\text { Bárbara }\end{array}$ & -16.676 \\
\hline 1701 & Nacaome & -11.817 & 401 & $\begin{array}{l}\text { Santa Rosa } \\
\text { de Copán }\end{array}$ & -15.867 \\
\hline 1707 & Langue & -10.107 & 611 & Pespire & -14.422 \\
\hline 401 & $\begin{array}{l}\text { Santa Rosa } \\
\text { De Copán }\end{array}$ & -9.738 & 1501 & Juticalpa & -11.546 \\
\hline 615 & $\begin{array}{l}\text { San Marcos } \\
\text { De Colón }\end{array}$ & -9.238 & 1701 & Nacaome & -11.473 \\
\hline 1706 & Goascorán & -8.117 & 1707 & Langue & -10.783 \\
\hline 605 & El Corpus & -7.845 & 615 & $\begin{array}{l}\text { San } \\
\text { Marcos de } \\
\text { Colón }\end{array}$ & -9.627 \\
\hline 1401 & $\begin{array}{l}\text { Ocotepe- } \\
\text { que }\end{array}$ & -7.491 & 107 & Tela & -9.567 \\
\hline 1601 & $\begin{array}{l}\text { Santa } \\
\text { Bárbara }\end{array}$ & -6.789 & 1801 & Yoro & -8.675 \\
\hline 1619 & $\begin{array}{l}\text { San José De } \\
\text { Colinas }\end{array}$ & -6.633 & 603 & $\begin{array}{l}\text { Concep- } \\
\text { ción de } \\
\text { Maria }\end{array}$ & -8.461 \\
\hline 603 & $\begin{array}{l}\text { Concepcion } \\
\text { De María }\end{array}$ & -6.476 & 605 & El Corpus & -7.949 \\
\hline 1807 & Olanchito & -6.081 & 1807 & Olanchito & -7.843 \\
\hline 816 & $\begin{array}{l}\text { Sabana- } \\
\text { grande }\end{array}$ & -5.817 & 601 & Choluteca & -7.424 \\
\hline 1704 & Aramecina & -5.400 & 1401 & $\begin{array}{l}\text { Ocotepe- } \\
\text { que }\end{array}$ & -6.862 \\
\hline 610 & Orocuina & -5.385 & 610 & Orocuina & -6.474 \\
\hline 1623 & $\begin{array}{l}\text { San Pedro } \\
\text { Zacapa }\end{array}$ & -5.188 & 1706 & Goascorán & -6.380 \\
\hline 602 & Apacilagua & -5.179 & 1001 & $\begin{array}{l}\text { La Espe- } \\
\text { ranza }\end{array}$ & -6.087 \\
\hline 1003 & $\begin{array}{l}\text { Colomon- } \\
\text { cagua }\end{array}$ & -5.017 & 1619 & $\begin{array}{l}\text { San José } \\
\text { de Colinas }\end{array}$ & -6.044 \\
\hline & $\begin{array}{l}\text { San Fran- } \\
\text { cisco De }\end{array}$ & & & & \\
\hline 1708 & Coray & -4.987 & 703 & Danlí & -5.942 \\
\hline 1307 & Guarita & -4.971 & 606 & El Triunfo & -5.940 \\
\hline 714 & Soledad & -4.768 & 714 & Soledad & -5.582 \\
\hline
\end{tabular}

Fuente: Elaboración propia en base a datos censales 1988 y 2001. 
Cuadro No. 7. Honduras: Municipios con mayor número de emigrantes recientes, 1988-83 y 2001-96.

\begin{tabular}{|c|c|c|c|c|c|}
\hline Cod & $\begin{array}{l}\text { Munici- } \\
\text { pios }\end{array}$ & $\begin{array}{c}\text { Emi- } \\
\text { grantes } \\
1988-83\end{array}$ & Cod & $\begin{array}{l}\text { Munici- } \\
\text { pios }\end{array}$ & $\begin{array}{c}\text { Emi- } \\
\text { grantes } \\
2001-96\end{array}$ \\
\hline 501 & $\begin{array}{l}\text { San Pedro } \\
\text { Sula }\end{array}$ & 15.742 & 501 & $\begin{array}{l}\text { San Pedro } \\
\text { Sula }\end{array}$ & 30.107 \\
\hline 801 & $\begin{array}{l}\text { Distrito } \\
\text { Central }\end{array}$ & 12.738 & 801 & $\begin{array}{l}\text { Distrito } \\
\text { Central }\end{array}$ & 23.924 \\
\hline 101 & La Ceiba & 5.864 & 101 & La Ceiba & 7.781 \\
\hline 601 & Choluteca & 5.253 & 1804 & El Progreso & 6.479 \\
\hline 1804 & El Progreso & 5.196 & 703 & Danlí & 6.221 \\
\hline 107 & Tela & 4.618 & 107 & Tela & 6.110 \\
\hline 703 & Danlí & 4.531 & 1807 & Olanchito & 5.742 \\
\hline 1501 & Juticalpa & 4.132 & 601 & Choluteca & 5.168 \\
\hline 1807 & Olanchito & 3.844 & 512 & La Lima & 4.890 \\
\hline 318 & $\begin{array}{l}\text { Siguatepe- } \\
\text { que }\end{array}$ & 2.708 & 209 & Tocoa & 4.696 \\
\hline 1701 & Nacaome & 2.698 & 1801 & Yoro & 4.538 \\
\hline 301 & $\begin{array}{l}\text { Comaya- } \\
\text { gua }\end{array}$ & 2.686 & 301 & $\begin{array}{l}\text { Comaya- } \\
\text { gua }\end{array}$ & 4.449 \\
\hline 209 & Tocoa & 2.626 & 1501 & Juticalpa & 4.296 \\
\hline 1627 & Las Vegas & 2.535 & 502 & Choloma & 4.260 \\
\hline 510 & $\begin{array}{l}\text { Santa Cruz } \\
\text { De Yojoa }\end{array}$ & 2.527 & 1601 & $\begin{array}{l}\text { Santa } \\
\text { Bárbara }\end{array}$ & 3.892 \\
\hline 512 & La Lima & 2.526 & 401 & $\begin{array}{l}\text { Santa Rosa } \\
\text { de Copán }\end{array}$ & 3.428 \\
\hline 208 & Sonaguera & 2.490 & 208 & Sonaguera & 3.368 \\
\hline 506 & $\begin{array}{l}\text { Puerto } \\
\text { Cortes }\end{array}$ & 2.393 & 1503 & Catacamas & 3.226 \\
\hline 401 & $\begin{array}{l}\text { Santa Rosa } \\
\text { De Copán }\end{array}$ & 2.306 & 201 & Trujillo & 3.025 \\
\hline 611 & Pespire & 2.302 & 1806 & Morazán & 2.965 \\
\hline 1503 & Catacamas & 2.289 & 510 & $\begin{array}{l}\text { Santa Cruz } \\
\text { de Yojoa }\end{array}$ & 2.935 \\
\hline
\end{tabular}

Fuente: Elaboración propia en base a datos censales 1988 y 2001
Cuadro No. 8. Honduras: Municipios con mayores Tasas de emigrantes recientes, 1988-83 y 2001-96 (por mil).

\begin{tabular}{|c|c|c|c|c|c|}
\hline Cod & $\begin{array}{l}\text { Munici- } \\
\text { pios }\end{array}$ & $\begin{array}{c}\text { Tasa de } \\
\text { Emigración } \\
\text { 1988-83 }\end{array}$ & Cod & $\begin{array}{l}\text { Munici- } \\
\text { pios }\end{array}$ & $\begin{array}{c}\text { Tasa de } \\
\text { Emigración } \\
2001-96\end{array}$ \\
\hline 1623 & $\begin{array}{l}\text { San Pedro } \\
\text { Zacapa }\end{array}$ & 52.33 & 1001 & $\begin{array}{l}\text { La Espe- } \\
\text { ranza }\end{array}$ & 44.31 \\
\hline 1001 & $\begin{array}{l}\text { La Espe- } \\
\text { ranza }\end{array}$ & 42.20 & 207 & $\begin{array}{l}\text { Santa Rosa } \\
\text { de Aguán }\end{array}$ & 32.00 \\
\hline 312 & $\begin{array}{l}\text { Ojos de } \\
\text { Agua }\end{array}$ & 37.68 & 1209 & $\begin{array}{l}\text { Mercedes } \\
\text { de Oriente }\end{array}$ & 29.70 \\
\hline 1627 & Las Vegas & 36.66 & 1601 & $\begin{array}{l}\text { Santa } \\
\text { Bárbara }\end{array}$ & 29.59 \\
\hline 1209 & $\begin{array}{l}\text { Merce- } \\
\text { des de } \\
\text { Oriente }\end{array}$ & 36.27 & 1406 & $\begin{array}{l}\text { La Encarna- } \\
\text { ción }\end{array}$ & 26.20 \\
\hline 718 & Yauyupe & 34.18 & 1624 & $\begin{array}{l}\text { San Vicente } \\
\text { Centenario }\end{array}$ & 26.16 \\
\hline 608 & Morolica & 34.06 & 1101 & Roatán & 25.75 \\
\hline 821 & $\begin{array}{l}\text { San Mi- } \\
\text { guelito }\end{array}$ & 33.78 & 821 & $\begin{array}{l}\text { San Migue- } \\
\text { lito }\end{array}$ & 23.63 \\
\hline 416 & $\begin{array}{l}\text { San Jeró- } \\
\text { nimo }\end{array}$ & 33.55 & 105 & La Masica & 23.39 \\
\hline 1015 & $\begin{array}{l}\text { Santa } \\
\text { Lucía }\end{array}$ & 31.72 & 306 & La Libertad & 22.94 \\
\hline 602 & $\begin{array}{l}\text { Apacila- } \\
\text { gua }\end{array}$ & 31.39 & 1102 & Guanaja & 22.69 \\
\hline 716 & Texiguat & 30.27 & 208 & Sonaguera & 22.65 \\
\hline 1211 & $\begin{array}{l}\text { San Anto- } \\
\text { nio del } \\
\text { Norte }\end{array}$ & 29.29 & 205 & Sabá & 22.53 \\
\hline & $\begin{array}{l}\text { San } \\
\text { Francisco }\end{array}$ & & & & \\
\hline 1708 & De Coray & 28.48 & 1620 & San Luís & 22.43 \\
\hline 717 & $\begin{array}{l}\text { Vado } \\
\text { Ancho }\end{array}$ & 28.06 & 410 & Florida & 22.12 \\
\hline 815 & Reitoca & 27.51 & 408 & $\begin{array}{l}\text { Dulce } \\
\text { Nombre }\end{array}$ & 22.07 \\
\hline 1010 & $\begin{array}{l}\text { San } \\
\text { Antonio }\end{array}$ & 27.44 & 1806 & Morazán & 21.28 \\
\hline 807 & $\begin{array}{l}\text { La Liber- } \\
\text { tad }\end{array}$ & 27.26 & 1514 & Mangulile & 21.18 \\
\hline 1705 & Caridad & 26.06 & 401 & $\begin{array}{l}\text { Santa Rosa } \\
\text { de Copán }\end{array}$ & 20.89 \\
\hline 611 & Pespire & 25.87 & 512 & La Lima & 20.82 \\
\hline 614 & San José & 25.83 & 416 & $\begin{array}{l}\text { San Jeró- } \\
\text { nimo }\end{array}$ & 20.71 \\
\hline
\end{tabular}

Fuente: Elaboración propia en base a datos censales 1988 y 2001. 
Cuadro No. 9. Honduras: Municipios con mayor número de inmigrantes recientes, 1988-83 y 2001-96.

\begin{tabular}{|c|c|c|c|c|c|}
\hline Cod & $\begin{array}{l}\text { Munici- } \\
\text { pios }\end{array}$ & $\begin{array}{c}\text { Inmi- } \\
\text { grantes } \\
\text { 1988-83 }\end{array}$ & Cod & $\begin{array}{l}\text { Munici- } \\
\text { pios }\end{array}$ & $\begin{array}{c}\text { Inmi- } \\
\text { grantes } \\
2001-96\end{array}$ \\
\hline 801 & $\begin{array}{l}\text { Distrito } \\
\text { Central }\end{array}$ & 42.769 & 501 & $\begin{array}{l}\text { San Pedro } \\
\text { Sula }\end{array}$ & 36.996 \\
\hline 501 & $\begin{array}{l}\text { San Pedro } \\
\text { Sula }\end{array}$ & 23.862 & 801 & $\begin{array}{l}\text { Distrito } \\
\text { Central }\end{array}$ & 35.376 \\
\hline 502 & Choloma & 8.253 & 502 & Choloma & 24.483 \\
\hline 1804 & El Progreso & 7.037 & 511 & Villanueva & 16.709 \\
\hline 101 & La Ceiba & 6.234 & 101 & La Ceiba & 9.128 \\
\hline 512 & La Lima & 5.180 & 1804 & ElProgreso & 7.349 \\
\hline 601 & Choluteca & 3.843 & 318 & $\begin{array}{l}\text { Siguatepe- } \\
\text { que }\end{array}$ & 5.109 \\
\hline 703 & Danlí & 3.748 & 512 & La Lima & 4.852 \\
\hline 301 & $\begin{array}{l}\text { Comaya- } \\
\text { gua }\end{array}$ & 3.637 & 510 & $\begin{array}{l}\text { Santa Cruz } \\
\text { de Yojoa }\end{array}$ & 4.716 \\
\hline 1501 & Juticalpa & 3.567 & 301 & $\begin{array}{l}\text { Comaya- } \\
\text { gua }\end{array}$ & 4.642 \\
\hline 1807 & Olanchito & 3.524 & 509 & $\begin{array}{l}\text { San } \\
\text { Manuel }\end{array}$ & 4.569 \\
\hline 318 & $\begin{array}{l}\text { Siguatepe- } \\
\text { que }\end{array}$ & 3.492 & 703 & Danlí & 4.461 \\
\hline 1503 & Catacamas & 3.467 & 506 & $\begin{array}{l}\text { Puerto } \\
\text { Cortés }\end{array}$ & 4.411 \\
\hline 107 & Tela & 3.466 & 601 & Choluteca & 4.407 \\
\hline 506 & $\begin{array}{l}\text { Puerto } \\
\text { Cortes }\end{array}$ & 3.394 & 201 & Trujillo & 4.360 \\
\hline 510 & $\begin{array}{l}\text { Santa Cruz } \\
\text { De Yojoa }\end{array}$ & 3.191 & 107 & Tela & 3.565 \\
\hline 201 & Trujillo & 3.111 & 1501 & Juticalpa & 3.551 \\
\hline 511 & Villanueva & 2.850 & 209 & Tocoa & 3.365 \\
\hline 209 & Tocoa & 2.787 & 1807 & Olanchito & 3.319 \\
\hline 103 & Esparta & 2.529 & 1503 & Catacamas & 2.769 \\
\hline 1803 & El Negrito & 2.332 & 401 & $\begin{array}{l}\text { Santa Rosa } \\
\text { de Copán }\end{array}$ & 2.515 \\
\hline
\end{tabular}

Fuente: Elaboración propia en base a datos censales 1988 y 2001.
Cuadro No. 10. Honduras: Municipios con mayores Tasas de Inmigrantes recientes, 1988-83 y 2001-96 (por mil).

\begin{tabular}{|c|c|c|c|c|c|}
\hline Cod & $\begin{array}{l}\text { Munici- } \\
\text { pios }\end{array}$ & $\begin{array}{c}\text { Tasa de In- } \\
\text { migración } \\
\text { 1988-83 }\end{array}$ & Cod & $\begin{array}{l}\text { Munici- } \\
\text { pios }\end{array}$ & $\begin{array}{l}\text { Tasa de In- } \\
\text { migración } \\
2000-96\end{array}$ \\
\hline 1101 & Roatán & 45.06 & 511 & Villanueva & 55.63 \\
\hline 204 & Limón & 38.45 & 504 & Pimienta & 48.02 \\
\hline 206 & Santa Fé & 36.69 & 1104 & Utila & 44.90 \\
\hline 106 & $\begin{array}{l}\text { San Francis- } \\
\text { co }\end{array}$ & 35.97 & 502 & Choloma & 41.96 \\
\hline 502 & Choloma & 33.93 & 509 & San Manuel & 37.89 \\
\hline 102 & El Porvenir & 33.03 & 102 & El Porvenir & 31.39 \\
\hline 1001 & $\begin{array}{l}\text { La Espe- } \\
\text { ranza }\end{array}$ & 31.82 & 1101 & Roatán & 29.93 \\
\hline 210 & $\begin{array}{l}\text { Bonito } \\
\text { Oriental }\end{array}$ & 31.71 & 823 & Santa Lucía & 27.92 \\
\hline 201 & Trujillo & 31.65 & 1405 & Fraternidad & 24.78 \\
\hline 207 & $\begin{array}{l}\text { Santa Rosa } \\
\text { De Aguán }\end{array}$ & 31.62 & 201 & Trujillo & 24.12 \\
\hline 105 & La Masica & 30.65 & 1615 & Petoa & 23.98 \\
\hline 509 & San Manuel & 30.04 & 505 & Potrerillos & 23.81 \\
\hline 512 & La Lima & 29.51 & 1513 & La Unión & 22.94 \\
\hline 1102 & Guanaja & 28.24 & 204 & Limón & 22.65 \\
\hline 504 & Pimienta & 27.22 & 826 & $\begin{array}{l}\text { Valle de } \\
\text { Angeles }\end{array}$ & 21.85 \\
\hline 823 & Santa Lucía & 26.27 & 512 & La Lima & 20.66 \\
\hline 1517 & San Esteban & 26.00 & 318 & $\begin{array}{l}\text { Siguatepe- } \\
\text { que }\end{array}$ & 20.63 \\
\hline 1627 & Las Vegas & 25.03 & 1011 & San Isidro & 20.50 \\
\hline 104 & Jutiapa & 24.98 & 817 & $\begin{array}{l}\text { San } \\
\text { Antonio de } \\
\text { Oriente }\end{array}$ & 19.69 \\
\hline 319 & $\begin{array}{l}\text { Villa De San } \\
\text { Antonio }\end{array}$ & 24.78 & 1102 & Guanaja & 19.55 \\
\hline 1103 & $\begin{array}{l}\text { José Santos } \\
\text { Guardiola }\end{array}$ & 23.43 & 706 & Jacaleapa & 19.52 \\
\hline
\end{tabular}

Fuente: Elaboración propia en base a datos censales 1988 y 2001. 
Cuadro No. 11. Honduras: Municipios con mayor saldo migratorio positivo reciente, 1988-83 y 2001-96

\begin{tabular}{|c|c|c|c|c|c|}
\hline Cod & $\begin{array}{l}\text { Munici- } \\
\text { pios }\end{array}$ & $\begin{array}{l}\text { Migra- } \\
\text { ción Neta } \\
\text { 1988-83 }\end{array}$ & Cod & $\begin{array}{l}\text { Munici- } \\
\text { pios }\end{array}$ & $\begin{array}{c}\text { Migración } \\
\text { Neta } 2001- \\
96\end{array}$ \\
\hline 801 & $\begin{array}{l}\text { Distrito } \\
\text { Central }\end{array}$ & 30.031 & 502 & Choloma & 20.223 \\
\hline 501 & $\begin{array}{l}\text { San Pedro } \\
\text { Sula }\end{array}$ & 8.120 & 511 & Villanueva & 14.361 \\
\hline 502 & Choloma & 6.372 & 801 & $\begin{array}{l}\text { Distrito } \\
\text { Central }\end{array}$ & 11.452 \\
\hline 512 & La Lima & 2.654 & 501 & $\begin{array}{l}\text { San Pedro } \\
\text { Sula }\end{array}$ & 6.889 \\
\hline 1804 & El Progreso & 1.841 & 509 & San Manuel & 3.922 \\
\hline 511 & Villanueva & 1.533 & 318 & $\begin{array}{l}\text { Siguatepe- } \\
\text { que }\end{array}$ & 2.197 \\
\hline 509 & San Manuel & 1.331 & 506 & $\begin{array}{l}\text { Puerto } \\
\text { Cortés }\end{array}$ & 2.010 \\
\hline 1101 & Roatán & 1.188 & 504 & Pimienta & 1.822 \\
\hline 1503 & Catacamas & 1.178 & 510 & $\begin{array}{l}\text { Santa Cruz } \\
\text { de Yojoa }\end{array}$ & 1.781 \\
\hline 506 & $\begin{array}{l}\text { Puerto } \\
\text { Cortes }\end{array}$ & 1.001 & 101 & La Ceiba & 1.347 \\
\hline 1803 & El Negrito & 969 & 201 & Trujillo & 1.335 \\
\hline 301 & Comayagua & 951 & 102 & El Porvenir & 1.335 \\
\hline 201 & Trujillo & 877 & 1006 & Intibucá & 1.054 \\
\hline 210 & $\begin{array}{l}\text { Bonito } \\
\text { Oriental }\end{array}$ & 876 & 1804 & El Progreso & 870 \\
\hline 1006 & Intibucá & 847 & 505 & Potrerillos & 785 \\
\hline 318 & $\begin{array}{l}\text { Siguatepe- } \\
\text { que }\end{array}$ & 784 & 806 & Guaimaca & 659 \\
\hline 106 & $\begin{array}{l}\text { San Fran- } \\
\text { cisco }\end{array}$ & 760 & 817 & $\begin{array}{l}\text { San Antonio } \\
\text { de Oriente }\end{array}$ & 636 \\
\hline 105 & La Masica & 752 & 823 & Santa Lucía & 592 \\
\hline 319 & $\begin{array}{l}\text { Villa De San } \\
\text { Antonio }\end{array}$ & 706 & 826 & $\begin{array}{l}\text { Valle de } \\
\text { Angeles }\end{array}$ & 530 \\
\hline 102 & El Porvenir & 698 & 1201 & La Paz & 450 \\
\hline 103 & Esparta & 688 & 708 & Morocelí & 448 \\
\hline
\end{tabular}

Fuente: Elaboración propia en base a datos censales 1988 y 2001.
Cuadro No. 12. Honduras: Municipios con mayor saldo migratorio negativo reciente, 1988-83 y 2001-96

\begin{tabular}{|c|c|c|c|c|c|}
\hline Cod & $\begin{array}{l}\text { Munici- } \\
\text { pios }\end{array}$ & $\begin{array}{c}\text { Migración } \\
\text { Neta 1988- } \\
83\end{array}$ & Cod & $\begin{array}{c}\text { Munici- } \\
\text { pios }\end{array}$ & $\begin{array}{l}\text { Migra- } \\
\text { ción Neta } \\
2001-96\end{array}$ \\
\hline 611 & Pespire & -2.151 & 107 & Tela & -2.545 \\
\hline 1701 & Nacaome & -1.752 & 1807 & Olanchito & -2.423 \\
\hline 615 & $\begin{array}{l}\text { San } \\
\text { Marcos de } \\
\text { Colón }\end{array}$ & -1.526 & 1801 & Yoro & -2.270 \\
\hline 1623 & $\begin{array}{l}\text { San Pedro } \\
\text { Zacapa }\end{array}$ & -1.524 & 703 & Danlí & -1.760 \\
\hline 605 & El Corpus & -1.456 & 1601 & $\begin{array}{l}\text { Santa } \\
\text { Bárbara }\end{array}$ & -1.755 \\
\hline 1707 & Langue & -1.435 & 410 & Florida & -1.578 \\
\hline 601 & Choluteca & -1.410 & 208 & Sonaguera & -1.556 \\
\hline 603 & $\begin{array}{l}\text { Concep- } \\
\text { ción de } \\
\text { María }\end{array}$ & -1.400 & 611 & Pespire & -1.556 \\
\hline 610 & Orocuina & -1.259 & 606 & El Triunfo & -1.436 \\
\hline 606 & El Triunfo & -1.250 & 1806 & Morazán & -1.359 \\
\hline 107 & Tela & -1.152 & 209 & Tocoa & -1.331 \\
\hline 602 & Apacilagua & -1.021 & 1620 & San Luís & -1.243 \\
\hline 716 & Texiguat & -885 & 1707 & Langue & -1.144 \\
\hline 1612 & Macuelizo & -853 & 306 & La Libertad & -1.105 \\
\hline 816 & $\begin{array}{l}\text { Sabana- } \\
\text { grande }\end{array}$ & -848 & 603 & $\begin{array}{l}\text { Concepción } \\
\text { de Maria }\end{array}$ & -1.046 \\
\hline 1003 & $\begin{array}{l}\text { Colomon- } \\
\text { cagua }\end{array}$ & -841 & 1313 & Lepaera & -1.045 \\
\hline 1627 & Las Vegas & -804 & 1701 & Nacaome & -964 \\
\hline & $\begin{array}{l}\text { San } \\
\text { Francisco }\end{array}$ & & & & \\
\hline 1708 & De Coray & -788 & 409 & El Paraíso & -933 \\
\hline 815 & Reitoca & -787 & 401 & $\begin{array}{l}\text { Santa Rosa } \\
\text { de Copán }\end{array}$ & -913 \\
\hline 703 & Danlí & -783 & 1619 & $\begin{array}{l}\text { San José de } \\
\text { Colinas }\end{array}$ & -911 \\
\hline 1706 & Goascorán & -761 & 605 & El Corpus & -891 \\
\hline
\end{tabular}

Fuente: Elaboración propia en base a datos censales 1988 y 2001. 
Cuadro No. 13. Honduras: Municipios con mayores Tasas de Migración Neta Reciente, 1988-83 y 2001-96 (por mil)

\begin{tabular}{|c|c|c|c|c|c|}
\hline Cod & $\begin{array}{l}\text { Munici- } \\
\text { pios }\end{array}$ & $\begin{array}{l}\text { Tasa de } \\
\text { Migra- } \\
\text { ción Neta } \\
1988-83\end{array}$ & Cod & $\begin{array}{l}\text { Munici- } \\
\text { pios }\end{array}$ & $\begin{array}{l}\text { Tasa de } \\
\text { Migra- } \\
\text { ción Neta } \\
2001-96\end{array}$ \\
\hline 1101 & Roatán & 32.15 & 511 & Villanueva & 47.82 \\
\hline 502 & Choloma & 26.19 & 504 & Pimienta & 38.44 \\
\hline 1103 & $\begin{array}{l}\text { José Santos } \\
\text { Guardiola }\end{array}$ & 21.86 & 1104 & Utila & 35.99 \\
\hline 106 & $\begin{array}{l}\text { San Fran- } \\
\text { cisco }\end{array}$ & 21.76 & 502 & Choloma & 34.66 \\
\hline 509 & San Manuel & 21.14 & 509 & $\begin{array}{l}\text { San } \\
\text { Manuel }\end{array}$ & 32.53 \\
\hline 204 & Limón & 20.77 & 102 & El Porvenir & 22.99 \\
\hline 823 & Santa Lucía & 20.36 & 823 & Santa Lucía & 21.55 \\
\hline 102 & El Porvenir & 19.04 & 1405 & Fraternidad & 18.49 \\
\hline 210 & $\begin{array}{l}\text { Bonito } \\
\text { Oriental }\end{array}$ & 17.82 & 1103 & $\begin{array}{l}\text { José Santos } \\
\text { Guardiola }\end{array}$ & 13.83 \\
\hline 320 & Las Lajas & 17.13 & 817 & $\begin{array}{l}\text { San } \\
\text { Antonio de } \\
\text { Oriente }\end{array}$ & 13.08 \\
\hline 206 & Santa Fé & 16.92 & 1011 & San Isidro & 13.05 \\
\hline 319 & $\begin{array}{l}\text { Villa De San } \\
\text { Antonio }\end{array}$ & 16.31 & 1302 & Belén & 12.87 \\
\hline 512 & La Lima & 15.12 & 826 & $\begin{array}{l}\text { Valle de } \\
\text { Angeles }\end{array}$ & 12.20 \\
\hline 207 & $\begin{array}{l}\text { Santa Rosa } \\
\text { De Aguán }\end{array}$ & 14.62 & 505 & Potrerillos & 10.74 \\
\hline 1517 & San Esteban & 13.43 & 706 & Jacaleapa & 9.65 \\
\hline 801 & $\begin{array}{l}\text { Distrito } \\
\text { Central }\end{array}$ & 12.93 & 1513 & La Unión & 9.53 \\
\hline 511 & Villanueva & 11.91 & 616 & $\begin{array}{l}\text { Santa } \\
\text { Ana de } \\
\text { Yusguare }\end{array}$ & 9.10 \\
\hline 504 & Pimienta & 11.74 & 318 & $\begin{array}{l}\text { Siguatepe- } \\
\text { que }\end{array}$ & 8.87 \\
\hline 105 & La Masica & 11.72 & 708 & Morocelí & 8.82 \\
\hline 1102 & Guanaja & 11.68 & 806 & Guaimaca & 7.65 \\
\hline 817 & $\begin{array}{l}\text { San } \\
\text { Antonio De } \\
\text { Oriente }\end{array}$ & 10.82 & 1615 & Petoa & 7.55 \\
\hline
\end{tabular}

Fuente: Elaboración propia en base a datos censales 1988 y 2001.
Cuadro No. 14. Honduras: Municipios con menores Tasas de Migración Neta Reciente, 1988-83 y 2001-96 (por mil)

\begin{tabular}{|c|c|c|c|c|c|}
\hline Cod & Municipios & $\begin{array}{c}\text { Tasa de } \\
\text { Migración } \\
\text { Neta } \\
\text { 1988-83 }\end{array}$ & Cod & $\begin{array}{l}\text { Munici- } \\
\text { pios }\end{array}$ & $\begin{array}{l}\text { Tasa de } \\
\text { Migración } \\
\text { Neta } \\
\text { 2001-96 }\end{array}$ \\
\hline 1623 & $\begin{array}{l}\text { San Pedro } \\
\text { Zacapa }\end{array}$ & -45.97 & 1001 & $\begin{array}{l}\text { La Espe- } \\
\text { ranza }\end{array}$ & -25.88 \\
\hline 312 & $\begin{array}{l}\text { Ojos De } \\
\text { Agua }\end{array}$ & -34.96 & 1209 & $\begin{array}{l}\text { Mercedes } \\
\text { de Oriente }\end{array}$ & -24.01 \\
\hline 821 & $\begin{array}{l}\text { San Migue- } \\
\text { lito }\end{array}$ & -32.66 & 1406 & $\begin{array}{l}\text { La Encar- } \\
\text { nación }\end{array}$ & -21.21 \\
\hline 608 & Morolica & -31.57 & 821 & $\begin{array}{l}\text { San Migue- } \\
\text { lito }\end{array}$ & -20.74 \\
\hline 1209 & $\begin{array}{l}\text { Mercedes De } \\
\text { Oriente }\end{array}$ & -30.57 & 1624 & $\begin{array}{l}\text { San Vicente } \\
\text { Centenario }\end{array}$ & -19.84 \\
\hline 1015 & Santa Lucía & -29.50 & 207 & $\begin{array}{l}\text { Santa Rosa } \\
\text { de Aguán }\end{array}$ & -19.70 \\
\hline 602 & Apacilagua & -28.11 & 1511 & Guayape & -16.86 \\
\hline 716 & Texiguat & -28.05 & 1213 & San Juan & -16.23 \\
\hline 1708 & $\begin{array}{l}\text { San Francisco } \\
\text { De Coray }\end{array}$ & -26.98 & 614 & San José & -15.95 \\
\hline 717 & Vado Ancho & -26.89 & 1705 & Caridad & -15.85 \\
\hline 815 & Reitoca & -24.82 & 1522 & Yocón & -15.44 \\
\hline 807 & La Libertad & -24.22 & 608 & Morolica & -15.26 \\
\hline 611 & Pespire & -24.18 & 611 & Pespire & -14.86 \\
\hline 416 & San Jerónimo & -24.14 & 410 & Florida & -14.79 \\
\hline 1213 & San Juan & -23.78 & 602 & Apacilagua & -14.68 \\
\hline 614 & San José & -23.57 & 1514 & Mangulile & -14.57 \\
\hline 718 & Yauyupe & -23.24 & 807 & La Libertad & -14.44 \\
\hline 1010 & San Antonio & -23.04 & 306 & La Libertad & -14.42 \\
\hline 1707 & Langue & -22.56 & 1707 & Langue & -13.98 \\
\hline 1705 & Caridad & -22.23 & 1015 & Santa Lucía & -13.72 \\
\hline 613 & San Isidro & -21.52 & 811 & Marale & -13.61 \\
\hline
\end{tabular}

Fuente: Elaboración propia en base a datos censales 1988 y 2001. 


\subsection{Principales Flujos Migratorios de toda la vida}

Hasta el año de 1988, los principales flujos migratorios mayores de 2,000 personas se produjeron principalmente hacia el Distrito Central, San Pedro Sula y otros municipios que albergan ciudades intermedias como Choloma, Puerto Cortés, El Progreso, La lima y la Ceiba.

El mayores flujos migratorios del país hasta 1988 se produjeron específicamente de San Pedro Sula a Choloma, San Pedro Sula a La Lima, Choluteca al Distrito Central, San Pedro Sula al Distrito Central y Distrito Central a San Pedro Sula.

En el censo de población del 2001 los principales flujos migratorios mayores de 2,000 personas se produjeron principalmente hacia el Distrito Central, San Pedro Sula y otros municipios que albergan ciudades intermedias como Choloma, Villanueva, La Lima, La Ceiba, El Progreso, Puerto Cortés.

El mayores flujos migratorios del país hasta el 2001 se produjeron de San Pedro Sula a Choloma, Distrito Central a San Pedro Sula, Choluteca al Distrito Central, San Pedro Sula a La Lima, San Pedro Sula a Villanueva, Danlí al Distrito Central, Juticalpa al Distrito Central, Santa Bárbara a San Pedro Sula (Diagrama No. 1).

\section{MIGRACIÓN INTERNA INTERMUNICIPAL RECIENTE.}

\subsection{Volumen}

En la migración reciente el número de personas residiendo en un municipio diferente al que residía hace cinco años antes del censo aumentó en las mediciones del período 1988-83 eran 232,572 migrantes y se aumentó a 312,622 migrantes en el 2001-96, creciendo a una tasa de $2.25 \%$. Sin embargo, en términos relativos disminuyó de $13.7 \%$ a $12.1 \%$.

\subsection{Emigrantes recientes}

Los municipios con mayor número de emigrantes recientes tanto en el período 1988-1983 como en el período 2001 -1996 son casi los mismos, en ellos sobresalen San Pedro Sula y el Distrito Central y los municipios que albergan a las principales ciudades del país. En todos ellos aumentó su número entre ambos períodos y fue más notorio en los municipios de las dos principales ciudades (cuadro No. 7).

Las mayores tasas de emigración reciente se manifestaron en municipios pequeños no tan poblados a excepción de La Esperanza, Santa Bárbara, La Lima y Santa Rosa de Copán. En ambos períodos se presenta una diversidad de municipios con las mayores tasas, solo se repite el patrón en La Esperanza, Mercedes de Oriente, San Miguelito, La Libertad y San Jerónimo (cuadro No. 8).

\subsection{Inmigrantes recientes.}

Los municipios con mayor número de inmigrantes recientes en ambos períodos son casi todos los mismos, solo aparece en el último período San Manuel y Santa Rosa de Copán. Entre ambos períodos se produjo un cambio significativo, en 1988-83 el que recibió el mayor número de inmigrantes recientes fue el Distrito Central, pero en el período 2001-96 fue San Pedro Sula, incluso la capital de la república redujo su flujo en el último período (cuadro No. 9).

El efecto de la inmigración fue reflejado mayormente en municipios que albergan ciudades intermedias y pequeñas, tal es el caso de Villanueva que en el período 2001-96 la tasa de inmigración reciente superó el cincuenta y cinco por mil, otros municipios donde el efecto se hizo sentir se localizan en el Valle de Sula, entre ellos Pimienta, San Manuel y Choloma, así como en los municipios insulares de Utila y Roatán (cuadro No. 10).

\subsection{Saldo migratorio reciente}

Los municipios con mayor saldo migratorio positivo reciente fueron Villanueva y Choloma que superaron en la primacía al Distrito Central y San Pedro Sula y se convirtieron en municipios altamente atractivos por la creciente generación de empleo en maquilas (cuadro No. 11).

Los municipios con mayor saldo migratorio negativo reciente (llegaron menos y salieron más) incluye más diversificación, a excepción de Tela en el norte y Pespire, El Triunfo, Langue y Concepción de María en el sur del país que tienen una larga tradición de perder poblaciones por emigración (cuadro No. 12).

El municipio de Villanueva tiene la tasa de migración neta reciente más elevada del país, que significa que por cada mil habitantes en el período 1996-2001 la población se incrementó en cuarenta y ocho por efecto de la migración (cuadro No. 13).

Los municipios de La Esperanza y Mercedes de Oriente tienen las tasas de migración neta reciente negativas más elevadas del país, que significa que por cada mil habitantes en el período 1996 - 2001 la población disminuyó en más de veinticuatro por efecto de la migración (cuadro No. 14).

\subsection{Principales Flujos Migratorios Recientes}

En el período 1988-83 y 2001-96 los principales flujos migratorios mayores de 1000 personas se produjeron principalmente hacia el Distrito Central, San Pedro Sula y otros municipios que albergan ciudades intermedias como Choloma, Villanueva, La lima y la Ceiba. El mayores flujos migratorios recientes del país en el período 1988-83 se produjeron de San Pedro Sula a Choloma, Choluteca al Distrito Central y de San Pedro Sula a Distrito Central.

En el período 2001-96 los principales flujos migratorios recientes se produjeron de San Pedro Sula a Choloma, San Pedro Sula a Villanueva y del Distrito Central a San Pedro Sula (Diagrama No. 2).

\section{BIBLIOGRAFÍA}

Instituto Nacional de Estadística. Censo de Población y Vivienda de Honduras 2001, Tegucigalpa, INE, 2003.

Flores Fonseca, Manuel. Origen de los Inmigrantes Internos en Tegucigalpa, Tegucigalpa, IIES-UNAH, 2002.

Flores Fonseca, Manuel. Migrantes Internos en Honduras, Tegucigalpa, IIESUNAH, 2001.

Flores Fonseca, Manuel. Estudios Demográficos de Honduras: Estado de la Población, 50 años de Crecimiento Demográfico, Hogares y Familias, Jefatura de Hogar, Resultados Seguimiento a Cairo, Déficit de Viviendas, Evolución Déficit de Viviendas 1999-2003, Tegucigalpa, IIES-UNAH, 2004.

Maguid, Alicia. El Estudio de las Migraciones en Honduras a través de Diversas Fuentes: Evaluación y Recomendaciones para Mejorar su Captación, Tegucigalpa, UDIP. UNAH, 1992.

Polanco, Juan J. Aspectos Característicos y Factores Determinantes de la Migración Interna en Honduras, 1974 - 1988. Tegucigalpa, UDIP-UNAH, 1992.

Rodriguez, Leticia. La Migración Interna en Honduras (1961 -1988), Tegucigalpa, UDIP-UNAH, 1991.

Rodríguez Vignoli, Jorge. Migración Interna en América Latina y El Caribe: Estudio Regional del Período 1980 - 2000, Serie Población y Desarrollo No. 50, Santiago de Chile, CELADE-CEPAL, 2004. 